\title{
UMA VISÃO MULTIPROFISSI ONAL HUMANIZADA NO TRATAMENTO DA PESSOA COM DEPENDÊNCIA QUÍMICA EM ENFERMARIA PSIQUIÁTRICA DE UM HOSPITAL GERAL NO PARANÁ
}

[A humanized multiprofessional view on the treatment of drug dependents in a psychiatric ward of a general hospital in Paraná]

[ U na visión multiprofesional humanizada en el tratamiento de la persona con dependencia química en enfermería psiquiátrica de un hospital general en Paraná]

\author{
Francine Giselle K eiko Yotoko Ferreira* \\ JaquelineA ndréia L uz** \\ Ladislao Obrzut-N eto*** \\ Katia A parecida Santos $* * * *$
}

RESUMO: Este artigo refere-se ao relato da proposta de tratamento da pessoa com dependência química em Enfermarias de Psiquiatria (EPs) de Hospital Geral, mais especificamente na Santa Casa de Irati - Paraná, que é hospital de referência para outros oito municípios vizinhos. 0 objetivo deste é divulgar 0 trabalho que vem sendo desenvolvido no campo das dependências químicas em hospital geral. Elaborou-se um plano terapêutico que possibilita aos profissionais da saúde intervir junto ao dependente químico no momento de crise, na prevenção da recaída e na reabilitação em um curto período de tempo, of erecendo suporte a este e à sua família, por intermédio de um atendimento rápido e eficaz. Para embasar a presente proposta, fez-se uma coleta de dados relativa ao ano de 2002, de pacientes internados por alcoolismo e outras drogas, concomitantemente com uma pesquisa bi bliográfica para estabelecer o perfil de pacientes que procuram este tipo de serviço.

PALAVRAS-CHAVE: Drogas ilícitas; Humanização da assistência; R eforma psiquiátrica.

\section{INTRODUÇÃO}

De acordo com a resolução da Reforma Psiquiátrica, as Enfermarias de Psiquiatria em Hospital Geral (EPs), representam um plano assistencial que vem propondo al ternativas aos hospitais psiquiátricos tradicionais, buscando

\footnotetext{
*A ssistente Social, Especialista em Dependências Químicas, Hospital Santa Casa de Irati.

**Psicóloga, Especialista em Dependências Químicas.

***M édico Psiquiatra, Especialista em Dependências Químicas, Hospital Santa Casa de Irati.

****Psicóloga, Graduada pela PUC- PR, Hospital Santa Casa de Irati.
}

evitar as internações prolongadas, o hospitalismo, a perda da identidade, de vínculos sociais e da cidadania, permitindo que os pacientes permaneçam o maior tempo possível em suas comunidades de origem. Sendo assim, o tema escol hido teve como ponto de partida o trabal ho que vem sendo desenvol vido na Santa Casa de I rati, onde constatouse que existe a necessi dade de reestruturação do tratamento da pessoa com dependêndencia química, o qual passa a ser tratado como qualquer pessoa que necessita de atenção médica, psicológica e social, procurando não repetir os estigmas de um hospital psiquiátrico convencional.

Desta forma, surgiu a necessidade de elaborar um plano terapêutico que atue no momento de crise, na prevenção da recaída e na reabilitação deste paciente em um curto período de tempo, dando suporte ao indi víduo e a sua família, por meio de atendimento rápido e eficaz. Porém, para chegar a um plano terapêutico mais humanizado, fazse necessário entender a evolução da psiquiatria ea reforma psiquiátrica na cidade de I rati, além de conhecer o perfil das pessoas com dependências químicas que são atendidas nesse município.

A ntes da iniciativa citada anteriormente, os doentes mentais eram encaminhados para um hospital psiquiátrico de outro município. A partir de 1983 houve a organização do serviço de Saúde M ental do Estado, com a criação do ambulatório de psiquiatria com uma equipe multiprofissional, a qual contava com enfermeira, assistente social, psicóloga e médico. 0 atendimento baseava-se em visitas domiciliares com a equipe multiprofissional para avaliar e observar a evolução do paciente na sua residência, considerando a pessoa com dependência química como um todo, ou seja, biopsicossocial.

Com o passar do tempo percebeu-se a necessidade de um aporte de internamento hospital ar não centrado nos padrões hospitalares da época, ou seja, de internamento

Cogitare Enferm 2005 mai/ago; 10(2):54-62 
compulsório, com 30 dias ou mais, mas sim, de internações nos leitos de urgência de psiquiatria, com um período de 48 a 72 horas, com observação e posterior encaminhamento para o ambulatório ou para o hospital psiquiátrico. $\mathrm{Na}$ modalidade de tratamento que estava sendo implantado, os pacientes eram internados em enfermaria de clínica médica sem nenhuma diferenciação de patologia. Sendo assim, ocorriam muitos problemas relacionados com preconceito pela equipe médica, que questionava, satirizava o doente mental e seu tratamento, na forma que estava sendo implantada. Corroborando, B otega ${ }^{(1)}$

a admissão de pacientes psiquiátricos em enfermarias de clínica médica, são fenômenos característicos nos últimos tempos. Essa última eventualidade traz pelo menos três grandes problemas: o manejo de pacientes psicóticos, às vezes agitados; a atitude dos outros profissionais em relação ao doente mental e a de seus familiares em relação ao doente mental e a oposição da administração e do corpo clínico do hospital em relação à admissão de doentes mentais (p.18).

Em 1999, criou-se na Santa Casa uma nova enfermaria, dedicada em parte para a psiquiatria, passando os pacientes para um local mais separado, diminuindo os problemas com a equipe médica e com os pacientes de outras patologias, indo em consonância à proposta do Sistema Ú nico de Saúde (SUS), que através de auditoria cobrava outros espaços e terapias para os pacientes internados. A tualmente conta-se com cinco enfermarias para tratamento de doentes mentais e dependentes químicos, separadas com divisória, que na maior parte do tempo permanece com as portas abertas, juntamente com doentes clínicos.

Existem vantagens e desvantagens em manter as portas trancadas "por representar certa coação sobre os pacientes, produzindo, em alguns casos, medo, revolta e baixa autoestima", por outro lado, pode representar tranqüilização para a equipe e mesmo para certos pacientes que vêem na porta trancada uma barreira contra impulsos incontroláveis, auto ou heteroagressivos. Em relação as portas abertas énecessário, segundo o autor, que haja internamentos voluntários, pois "uma enfermaria que recebe pacientes internados contra a vontade própria dificilmente pode funcionar com portas abertas, com livre circulação..." (2:28-9).

Esta política de portas abertas é uma das propostas da R eforma Psiquiátrica, pois proporciona mais liberdade aos pacientes. Porém, é necessário ficar claro que uma uni dade aberta implica seleção de pacientes, com tendência a que doentes graves sejam transferidos para hospitais em outras regiões.

A s principais vantagens das EPs sobre os hospitais psiquiátricos são a proximidade ao acesso da população, favorecendo a continuidade da assistência, bem como 0 tratamento mais precoce dos distúrbios mentais, diminuindo a cronificação, na qual o doente passa a ser visto como uma pessoa semel hante aos outros. Existem também mel hores recursos de diversas especialidades médicas, facilitando 0 reconhecimento e o tratamento de doenças e intercorrências clínicas (2:31)

\section{DESCRIÇÃO DA EXPERIÊNCIA}

A ntes de el aborar a proposta de tratamento, a equipe de saúde da Santa Casa, considerou importante conhecer qual o tipo de dependência química de maior ocorrência na região, bem como caracterizar as pessoas que procuram tratamento. Para tanto fez um levantamento por intermédio dos prontuários de pacientes que estiveram em tratamento durante 0 ano de 2002.

Segundo o sistema de internação da Santa Casa de I rati, pôde-se constatar que a segunda causa de internação nesta instituição é devido à ingestão de ál cool. A pesar de não haver estudos na região em relação a esse número de internações, evidencia-se que, pelo fato da região ter sido colonizada por imigrantes ucrainos e poloneses, a ingestão de álcool éum hábito comum desde o início da adol escência.

Os membros de sociedades claramente normativas, em termos étnicos-culturais, ou em termos religiosos, ao se deslocarem para ambientes diferentes dos de sua origem são expostos a esse mesmo tipo de ambivalência, colocando-se em posição de risco em relação a formas patológicas de ingestão de álcool (3:132).

Desta forma, entende-se que a mudança de estrutura social pode estimular comportamentos que levem à ingestão de álcool como redução de tensão e ansiedade. A ssim,

o uso do álcool é cultural, sendo permitido em quase todas as sociedades do mundo. Informações sobre saber beber com responsabilidade e as conseqüências do uso inadequado de álcool, ainda são insuficientes e não contemplam a população de maior risco para o consumo, que são adolescentes e adultos jovens ${ }^{(4: 17)}$.

Outra hipótese é o fato do hospital ser o único da região, portanto de referência para os outros municípios, e por isto aumenta o número de internações, que se concentram na Santa Casa de I rati.

Vale ressaltar que, juntamente com o consumo do álcool, aproximadamente $90 \%$ dos pacientes internados são dependentes do tabaco, o que pode estar associado diretamente à agricul tura da região queé o plantio de fumo, o que facil ita 0 acesso, principal mente, pela prática desde a infância em fazer o "cigarro de palha". Outras drogas também fazem parte do quadro de consumo de substâncias dos pacientes internados, como maconha, cocaína, inal antes e em menor freqüência ansíoliticos e anfetaminas, segundo dados coletados dos prontuários dos pacientes, com consentimento formal da Direção Técnica da Santa Casa de Irati, durante 0 ano de 2002, conforme pode ser observado na tabela que segue. 
Tabela 1 - Pacientes internados em enfermarias psiquiátricas na Santa Casa de Irati por alcoolismo - 2002

\begin{tabular}{lcc}
\hline Sexo & $\mathrm{N}^{\circ}$ de Pacientes & $\%$ \\
\hline Masculino & 225 & 93,75 \\
Feminino & 15 & 6,25 \\
\hline Total & 240 & 100 \\
\hline
\end{tabular}

FONTE : Sistema de Prontuários da Santa Casa de Irati

O bserva-se na tabela 1 que a maioria dos pacientes internados são do sexo masculino (225 pacientes), enquanto que em pacientes do sexo feminino o número de internamentos é bastante reduzido (15 pacientes). Segundo Griffith ${ }^{(5)}$, o homem tem seu padrão de ingestão diferente da mulher.

Se ela é dona-de-casa, provavelmente bebe mais em casa que no bar. É freqüente ela comprar no armazém ou supermercado uma certa quantidade que consome em casa [...] a preocupação não é com o horário de abertura dos bares, nem com os horários de encontros de negócios, mas com o horário de abertura do armazém, com o período de ausência do marido... (p. 113).

Percebe-se ainda, que as diferenças entre homens e mulheres variam na proporção, porque

as mulheres começam a beber mais tarde, bebem menos, intoxicam-se menos e apresentam menor prevalência de alcoolismo, que, nelas, tem algumas características distintas em relação ao al coolismo masculino ${ }^{(3: 133)}$.

Essas diferenças podem caracterizar-se pel o fato da mulher sofrer maior estigma social, levando-a a manifestar comportamentos diferenciados em rel ação ao homem, pois geralmente o consumo é solitário e às escondidas, o que faz com que cheguem ao tratamento com maiores complicações biopsicossociais. A lém disso, nos parece que o número reduzido de mulheres que foram internadas na Santa Casa de I rati, seja devido à fal ta de preparo por parte dos profissionais em saber como abordar a questão do al cool ismo feminino, o que é um problema provavelmente em várias instituições, que pode estar relacionado com a falta de treinamento para 0 atendimento a este tipo de clientela.

Sendo assim, percebe-se a importância de treinamentos para a equipe que trabal ha com dependentes químicos, principalmente no momento da abordagem inicial, para que o profissional saiba identificar o uso ou não de substância e a sua relação com a queixa principal. Desta forma, o treinamento e reuniões com a equipe que trabal ha com o paciente dependente químico faz-se necessária, porque "são nessas reuniões que os problemas e as decisões mais rel evantes devem ser discutidos e resolvidos" (2:30).

Tendo em vista o número elevado de internações por alcoolismo, o tratamento do dependente químico na Santa Casa de I rati é voltado para a questão do álcool, porém a equipe que trabal ha no setor e as pessoas que têm contato com estes pacientes terão de estar capacitadas para tratar de pessoas que fazem uso de outros tipos de drogas.

Tabela 2 - Pacientes internados em enfermarias psiquiátricas na Santa Casa de I rati por outras drogas - 2002

\begin{tabular}{lcc}
\hline Sexo & $\mathrm{N}^{\circ}$ de Pacientes & $\%$ \\
\hline Masculino & 07 & 63,64 \\
Feminino & 04 & 36,36 \\
\hline Total & 11 & 100 \\
\hline
\end{tabular}

FONTE: Sistema de Prontuários da Santa Casa de Irati

Desta forma, pode-se observar na tabela 2 que 0 número de pacientes internados por outros tipos de drogas apresenta-se pequeno em comparação com o número de pacientes internados por alcoolismo, como mostra a tabela 1. Constata-se ainda, que apesar de o maior número ser para o sexo masculino, há ocorrência acentuada para o sexo feminino. Ainda com a finalidade de caracterizar os pacientes internados no período de 2002, levantou-se a média de permanência, conforme apresentado nas tabelas 3 e 4 a seguir.

Tabela 3- Tempo de permanência dos pacientes internados em enfermarias psiquiátricas na Santa Casa de Irati por alcoolismo- 2002

\begin{tabular}{lcc}
\hline Dias & $\mathrm{N}^{\circ}$ Pacientes & $\%$ \\
\hline $01-05$ & 79 & 32,91 \\
$06-10$ & 112 & 46,69 \\
$11-15$ & 35 & 14,58 \\
$16-20$ & 10 & 4,16 \\
$21-25$ & 03 & 1,25 \\
$26-30$ & 01 & 0,41 \\
\hline Total & 240 & 100 \\
\hline
\end{tabular}

FONTE: Sistema de Prontuários da Santa Casa de I rati 
Tabela 4- Tempo de permanência dos pacientes internados em enfermarias psiquiátricas na Santa Casa de Irati por outras drogas- 2002

\begin{tabular}{lcc}
\hline Dias & $\mathrm{N}^{\circ}$ Pacientes & $\%$ \\
\hline $01-05$ & 02 & 18,18 \\
$06-10$ & 04 & 36,36 \\
$11-15$ & 03 & 27,28 \\
$16-20$ & 01 & 9,09 \\
$21-25$ & 01 & 9,09 \\
$26-30$ & - & - \\
\hline Total & 11 & 100 \\
\hline
\end{tabular}

FONTE: Sistema de Prontuários da Santa Casa de I rati

A maioria dos pacientes concentrou-se no período correspondente de 06 a 10 dias de internamento, que está de acordo com o preconizado pela portaria ministerial $n$ o 817 de 30 de abril de 2002, que dispõem sobre o tempo de permanência para pacientes com Transtornos Decorrentes do Uso Prejudicial de Álcool e/ ou Outras Drogas e pacientes em Síndrome de A bstinência Decorrente do U so Prejudicial e/ ou Dependência de Álcool e Drogas, cujo limite é de quinze diárias por $A$ utorização de Internamento Hospitalar (AIH) ${ }^{(6)}$. hospital,

Quando o paciente chega ao pronto socorro do

a maioria dos casos, está relacionado a estados de intoxicação e abstinência, porém complicações médicas, acidentes, ferimentos por arma, comportamento suícida e violência costumam acompanhar estes casos ${ }^{(7: 17)}$

A proposta de tratamento da pessoa com dependência química do Hospital Santa Casa de Irati, foi elaborada nos pressupostos da R eforma Psiquiátrica, considerando a portaria ministerial $n-817 / 02$ e como visto, o tratamento do dependente químico em EPs de hospital geral tem como objetivo inicial a desintoxicação, a qual pode ser entendida como

um processo relativamente rápido, se entendido apenas no seu componente metabólico. M as se o caso é grave o suficiente para ser hospitalizado, então deve-se aproveitar esse período para a conscientização do paciente e reforço do vínculo terapêutico, não se confundindo a desintoxicação- etapa primeira do tratamento- com o tratamento propriamente dito que inicia quando este termina ${ }^{(8: 153)}$.

A ssim, esses pacientes são recepcionados primeiramente pelo médico generalista e equipe de enfermagem, os quais fazem a abordagem inicial. Desta forma, a abordagem é o primeiro passo a ser dado no tratamento das dependências químicas.

$\mathrm{N}$ a prática do dia-a-dia, o médico ou o terapeuta são envolvidos com diferentes níveis de abordagens que vão desde as salas de emergências de um hospital, unidade de desintoxicação, sala de consultório, encaminhamentos ou procura de tratamentos até familiares ou pessoas envolvidas pedindo orientação, e que para cada uma dessas situações utilizam-se técnicas diferentes de abordagem ${ }^{9: 411}$.

Os profissionais que trabal ham neste setor, médicos, equipe de enfermagem e recepcionistas, devem estar orientados quanto ao atendimento a este tipo de paciente, desde a recepção, que terá que coletar informações a respeito do mesmo, pois

é comum que o paciente por conta do estado de intoxicação, não seja capaz de fornecer informações mínimas, estas devem ser obtidas com acompanhantes ou policiais, sempre que possível, uma vez que os pacientes chegam a estes serviços inconscientes. A manutenção das funções vitais é o principal objetivo da assistência prestada. U m exame físico e psíquico completo, exames laboratoriais e análises toxicológicas devem ser realizados pela freqüência de ferimentos, infecção pulmonar, insuficiência do funcionamento hepático e alterações neurológicas (7:131).

Esses devem ser os primeiros passos no atendimento ao paciente, que em seguida passará para uma reavaliação. Para isso, acredita-se ser de grande importância um protocolo para 0 atendimento do paciente que chega ao pronto socorro por intoxicação e abstinência por álcool e outras drogas, no sentido de verificar qual o nível de comprometimento deste e o melhor tipo de tratamento de acordo com o seu nível de dependência e os critérios de el egibilidade da Santa Casa de Irati. Entende-se por elegibilidade "uma condição para a aceitação do paciente no serviço, baseados no grau de comprometimento do paciente por causa da dependência" (7:26).

De acordo com pesquisas realizadas com vários autores, em relação aos critérios de internação, optou-se pelos que mais se assemelham aos já empregados no hospital. Os critérios que são utilizados são: intoxicação grave, abstinência grave, complicações clínicas, comorbi dades psiquiátricas, insucesso de tratamentos menos intensivos e quando o uso em si é um risco para o paciente e para outras pessoas (risco de suícido, desvinculação social e familiar, auto e heteroagressão). Os casos que não se enquadram nesses critérios são encaminhados para outros serviços, como ambulatório e grupos de Alccólicos A nônimos (AA) ${ }^{(5,12)}$.

Ressaltamos que, depois da avaliação inicial e da abordagem diagnóstica realizada pelo médico, de acordo com os critérios já mencionados, é importante clarificar de forma teórica cada um desses critérios, a fim de demonstrar o perfil do paciente dependente químico atendido em EPs de hospital geral.

A intoxicação por substância, caracteriza-se pelo 
desenvolvimento de uma síndrome reversível específica de determinadas substâncias que ocorreu devido à recente ingestão de uma substância (diferentes substâncias podem produzir síndromes similares ou idênticas); alterações comportamentais ou psicológicas clinicamente significativas e mal adaptativas devido ao efeito da substância sobre o Sistema N ervoso Central, por exemplo, humor instável, prejuízo cognitivo, comprometimento da memória, (prejuízo no funcionamento social ou ocupacional), que se desenvolvem durante ou logo após o uso da substância; os sintomas não devem a uma condição médica geral nem são mais bem explicados por outro transtorno mental ${ }^{(10)}$.

Os critérios para a abstinência de substância são através do desenvolvimento de uma síndrome específica de determinada substância devido à cessação (ou redução) do uso pesado e prolongado desta; a síndrome específica da substância causa sofrimento ou prejuízo clinicamente significativo no funcionamento social, ocupacional ou em outras áreas importantes da vida do indivíduo; os sintomas não devem a uma condição médica geral nem são mais bem explicados por outro transtorno mental ${ }^{(10)}$.

E m relação às complicações clínicas, estas

proporcionam um critério objetivo da gravidade da dependência. A bordá-las de modo preciso e precoce é importante por vários motivos. M uitas delas, quando detectadas no início, são passíveis de tratamento e recuperação completa... ${ }^{(11: 17)}$.

Dessa forma, serão descritas as complicações clínicas que podem ocorrer em pacientes dependentes de álcool, visto que, como dito anteriormente constitui o foco principal do tratamento nas EPs da Santa Casa de Irati, devido ao al to número de internações.

De acordo com Griffith (5:93), "o alcoolismo causa lesões físicas devido a muitos efeitos diretos e indiretos ao organismo", é o que podemos chamar de complicações clínicas, tais como: acidentes, alterações sangüíneas, problemas nos ossos e articulações, lesão cerebral, demência alcoólica, degeneração cerebelar, ambliopia alcoólica, câncer, problemas pulmonares, epilepsia, síndrome fetal do al coolismo, arritmias cardíacas, miocardiopatia alcoólica, hipertensão, hipoglicemia, cirrose hepática, hepatite alcoólica, fígado gorduroso, carcinoma no fígado, esofagite, gastrite, pancreatite, neuropatia periférica, disfunção testicular e impotência. Há pacientes que não admitem a relação entre seu consumo de drogas e as complicações citadas, mas a presença de tais complicações podem estimulá-los a buscar a abstinência, aceitando permanecer em tratamento ${ }^{(11)}$.

Os profissionais que trabal ham com as pessoas que fazem uso e abuso de drogas, em especial o alcoolismo, devem dar importância ao componente físico na avaliação e no plano de tratamento. Da mesma forma, todos os que trabal ham no campo médico deveriam estar al ertas para as possibilidades de que um alcoolismo não detectado traz inúmeros quadros clínicos. A ssim, além dos problemas clínicos mencionados, também os problemas psiquiátricos e sociais estão relacionados ao consumo abusivo de álcool e outras drogas. Há muitas evidências que os transtornos psiquiátricos ocorrem concomitantemente com o uso de substâncias psicoativas.

No tratamento de dependência química em E Ps de hospital geral, é importante ressaltar que, além da intoxicação e da síndrome da abstinência, geralmente os quadros mais comuns, surgem também em pessoas com algum tipo de transtorno psiquiátrico, chamado comorbidade psiquiátrica, que é:

a ocorrência conjunta de dois ou mais transtornos mentais ou com outras condições clínicas gerais [...] investigar a presença de comorbidades entre os usuários de álcool e drogas é importante sob vários aspectos [...], a melhora do transtorno psiquiátrico associado pode ser benéfica para a evolução do quadro de dependência estabelecido (11:18).

Os tipos de transtornos mais comuns são: demência, delirium, psicose (esquizofrenia), transtorno de humor (bipolar, distimia, depressão etc), transtornos ansiosos (pânico, fobia, transtorno obsessivo compulsivo), déficit de atenção/hiperati vidade e transtornos de personalidade. A lém desses quadros, há outras condições para a internação, tais como risco de suicídio, ausência de suporte social adequado (família, amigos etc), auto e heteroagressão e até a necessi dade de aumentar a motivação de pacientes que não tiveram evolução em outros tratamentos.

Explanadas as situações que norteiam o processo seletivo do paciente em relação a sua internação na EPs, deve-se observar que esses critérios só poderão real mente ser válidos se houver o engajamento dos profissionais da área da saúde no momento da abordagem diagnóstica, ou seja, de nada vale existir protocolos eficazes, se os profissionais envolvidos não estão devidamente conscientizados da importância desta etapa na continuidade do tratamento. Sendo assim, acredita-se que o trabal ho integrado desses profissionais seja fundamental para 0 processo, e quem deve encabeçar essa idéia é o chefe do serviço de psiquiatria, que por meio de uma postura aberta, possa acompanhar essa reestruturação e dar suporte necessário.

Tendo em vista as várias especiali dades médicas que fazem plantão em um hospital geral, e considerando que 0 paciente em abstinência ou intoxicado será atendido por um desses profissionais, acredita-se ser de grande importância a preparação desses profissionais em todos os níveis de abstinências à saúde, pois

boa parte dos dependentes químicos entram em contato com o sistema de saúde devido a complicações decorrentes do consumo. Desse modo, o médico generalista é o seu primeiro contato com a rede de atendimento. Torna-se, desse modo, fundamental para o estabelecimento do diagnóstico precoce e para a motivação destes indivíduos a buscar ajuda especializa- 
da. Eis a importância do médico de todas as especialidades para a qualidade de vida destes indivíduos ${ }^{(11: 20)}$.

Desta forma, de acordo com a abordagem inicial realizada pelos médicos generalistas,

dependentes severos, ou que apresentam um quadro clínico ou psíquico importante, são pacientes que precisam ser tratados em nível hospitalar, pois uma tentativa de tratá-los em nível ambulatorial pode ocasionar o fracasso total do tratamento (12:153).

0 paciente depois de avaliado na admissão pelo médico e enfermagem, entra no hospital sem objetos cortantes, desodorantes ou outras drogas, sendo encaminhado para a enfermaria acompanhado do auxiliar de enfermagem, o qual irá medicá-lo conforme prescrição. 0 paciente adicto permanece de um dia até uma semana em processo de desintoxicação e após esse período permanece com medicação psicotrópica, vitaminas e outros fármacos, conforme a necessi dade. Concomitantemente participam de atividades de ajuda como higiene e orientação de pacientes recém admitidos.

A enfermagem possui muitas funções dentro de um hospital geral e as quais são específicas de cada setor. Para atuar nas EPs os profissionais de enfermagem necessitam de um treinamento especial eespecífico, a fim de poder dar continuidade ao tratamento. A lém disso, essa equipe precisa atender aos requisitos necessários para fazer parte da equipe, diferentemente dos outros setores do hospital, que seguem uma escala geral. Dessa forma, percebeu-se a necessidade de manter uma mesma equipe, pelo fato de estarem sempre acompanhando a evolução de um mesmo paciente, podendo assim se aprofundar e, além disso, interagir melhor com a equipe. Os requisitos necessários para esses profissionais, conforme verificado na prática, são: 0 interesse pela questão da dependência química, a habilidade no manejo com essa clientela, postura profissional e ética perante os outros setores do hospital, disponibilidade de tempo para participar de reuniões e treinamentos, assim como o interesse e a humildade para aprender.

Neste sentido, a assistência de enfermagem, dividese em duas fases: desintoxicação e manutenção da abstinência. $\mathrm{Na}$ primeira, deve-se fazer um levantamento das necessidades básicas af etadas (nutrição, condições de higiene, hidratação, integridade física, entre outros); verificar sinais vitais para detectar possíveis anormal idades e fazer avaliação do estado em que o paciente chega na enfermaria; se delirante ou alucinado, colocá-lo em lugar tranqüilo e bem iluminado; contê-lo fisicamente se agitado e risco de machucar-se (conforme prescrição médica); permanecer junto ao paciente procurando tranqüilizá-lo, principalmente nas duas situações anteriores ${ }^{(13)}$.

$\mathrm{N}$ a segunda fase, o paciente ainda sente bastante desconforto por estar abstinente e permanecerá al guns dias internado, assim a equipe de enfermagem deve ter os seguintes procedimentos: procurar estabelecer um relacionamento de confiança com o paciente; não criticar ou menosprezar o seu comportamento; oferecer apoio quando o mesmo mostrar-se ansioso devido a falta de substância; estabelecer limites na presença de comportamentos manipulativos; orientação e supervisão dos cuidados físicos ${ }^{(13)}$.

A lém desses itens, outros tópicos referentes à dependência química devem ser de conhecimento da equipe de enfermagem. Para isso, são elaborados treinamentos específicos para cada tipo de substância, assim como 0 manejo com o paciente, o qual é realizado mensalmente pela equipe terapêutica.

Vale ressaltar que no posto de enfermagem existe um quadro com os principais cuidados com o paciente, visto que havia dificuldades de manter os combinados feitos previamente, assim a implantação do quadro facilitou a visual ização para toda a equipe. $N$ as EPs existe um livro de ocorrência, no qual todos os profissionais que entram em contato com os pacientes fazem as suas anotações, para que a equipe esteja atual izada de todos os acontecimentos que ocorreram no período, facilitando a abordagem com 0 paciente.

Como descrito anteriormente, o serviço de psiquiatria permanecerá com visitas médicas diárias aos pacientes a fim de prescrever a medicação, avaliar o estado físico e mental, assim como determinar os combinados especiais para cada paciente. N este sentido, 0 médico psiquiatra deve ser um profissional disponível para qualquer intercorrência que ocorra nas EPs, bem como promover e participar ativamente de reuniões e treinamentos.

Os serviços de psicologia e serviço social fazem contato com os pacientes e seus familiares, realizando grupos e reuniões, al ém de entrevistas psiquiátricas com os pacientes que estiverem desintoxicados. Este método de coleta de dados clarificará a história do paciente, assim como norteará o tratamento e a motivação para a mudança do comportamento aditivo. N eumann ${ }^{(8)}$ afirma que

\footnotetext{
é preciso estabelecer diagnóstico do nível de comprometimento nas diversas áreas passíveis de serem acometidas: psicológica, social, ocupacional, física, legal etc. 0 nível de comprometimento indicará, então o nível requerido de atuação ou de intervenção terapêutica ${ }^{(p .}$ 163) $^{\text {. }}$
}

A intervenção terapêutica sempre irá se basear no momento pelo qual o paciente está vivendo, o que faz com que o tratamento seja personificado, ou seja, voltado para cada pessoa em particular. Isto é confirmado na citação: "oferecer um ambiente calmo, arejado, adequadamente iluminado, em que lhe dê continuamente referência de tempo, espaço, bem como um tratamento personificado, é medida bastante eficaz" (12:158).

Por meio dos dados verificados na entrevista psiquiátrica pode-se avaliar o nível de motivação do paciente, o qual é anexado junto ao prontuário do paciente 
para que todas as pessoas envolvidas no tratamento estejam atualizadas com o tipo de intervenção que será empregada. Não basta saber se a dependência existe e quão grave se manifesta no indivíduo. É preciso compreender também sua motivação para a mudança.

0 modelo teórico, desenvolvido por Prochaska e Diclemente ${ }^{(14)}$, o qual foi adotado pela Santa C asa de I rati, auxilia o planejamento para cada paciente. Quaisquer abordagens com dependentes de drogas devem respeitar 0 estágio de motivação de cada um destes; são seis estágios e para cada um deles há uma conversa mais efetiva e adequada:

1. 0 primeiro estágio éa pré-contemplação, no qual o paciente não tem idéia do problema nem planos de mudar, acha que seu consumo de drogas não faz mal e está sob controle, assim é melhor evitar o confronto.

2. 0 segundo estágio é o da contemplação, no qual o paciente percebe um problema, mas está ambival ente para promover mudança; neste estágio o paciente deve ser sensibilizado objetivamente.

3. 0 terceiro estágio é o da determinação, em que o paciente percebe que tem o problema e que precisa promover mudanças e pede ajuda, devendo o terapeuta oferecer soluções e negociar planos de abordagem.

4. 0 quarto estágio é caracterizado pela ação e o paciente está pronto para começar mudanças. N esse período é necessário prover o suporte, definir a assistência a ele e, a família deve mostrar-se disposta a participar do tratamento.

5. 0 quinto estágio é o da manutenção, no qual há a incorporação da mudança ao estilo de vida, sendo importante reforçar o sucesso, reavaliar a farmacoterapia, aplicar a prevenção de recaí da e aval iar a situação de risco.

6. 0 sexto estágio, chamado de recaída, é aquele no qual o paciente retorna para a contemplação ou précontemplação; neste estágio o profissional deve reforçar para retomar e continuar o tratamento e solicitar a participação da família. Para isso, a equipe dá prioridade ao diálogo sem confrontos, a fim de fazer com que o próprio paciente se auto avalie. Nesse período pode-se utilizar técnicas como o quadro de análise de vantagens e desvantagens de usar e não usar substância (14:173-195).

Todos esses conteúdos são trabal hados diariamente, coordenados pelas técnicas (profissionais de psicologia e de serviço social) e divididos em dois grupos principais: grupo de prevenção de recaída e grupo de sentimentos. 0 grupo de prevenção de recaídas, é baseado no enfoque cognitivo-comportamental de M arlatt, pois segundo K napp (14),

0 modo de beber do indivíduo é apenas o ponto de partida para a modificação de todo um estilo de vida, de um jeito de ser no mundo. A ssim como, ao longo da vida, ele não administrou seu beber de forma adequada e saudável, provavelmente não conseguiu fazer em relação a muitos outros aspectos da vida. A terapia, então, auxilia o indivíduo a refazer a sua história não através do seu terapeuta na relação transferencial, mas através da apreciação consciente e remodelação das formas inadequadas de viver, antigo campo fértil de problemas relacionados ao beber (p.177).

Dessa forma, os pacientes relatam a forma pela qual vão lidar com as situações de risco, manejo da fissura etc. É através do grupo que o paciente vai começar a pensar no que fazer para preencher o "vazio" que a droga deixou. Q uando os pacientes começam a pensar em outras atividades e novos comportamentos, começam a estruturar em si mesmo novas crenças.

0 indivíduo, [...] aprendeu e construiu um sistema de crenças equivocadas e distorcidas acerca de seu relacionamento com essa substância. Tais crenças são mantidas e reforçadas continuamente no decurso desse envolvimento [...]. Portanto, uma das primeiras e mais importantes intervenções terapêuticas na abordagem cognitiva é a identificação e a modificação do sistema de crenças distorcidas, subjacentes ao uso. Somente então o indivíduo estará apto a engajar-se na segunda fase do tratamento, que é a identificação e o manejo dos estímulos de alto risco (14:175)

0 paciente trabalhando em cima de novas crenças, na qual ele vai precisar conviver com vários tipos de sentimentos, tanto bons quanto ruins e que diferentemente do tempo de ativa, vai precisar buscar novas formas de lidar com os problemas, assim como tolerar a frustração de não obter a satisfação rápida que costumava ter com o uso de substância.

0 manejo da fissura também é um tema trabalhado em grupo, pois é visto como algo normal no caminho da recuperação e vai auxiliar o paciente a lidar com os próprios limites. A ssim como a fissura, o lapso e a recaída também são abordados como processos comuns no tratamento da dependência química. No modelo cognitivocomportamental de M arlatt, "recaída refere-se a retomada do antigo padrão de consumo alcoólico enquanto um episódio de ingestão é entendido como um lapso". Esses conceitos são esclarecidos no grupo, pois entende-se que os pacientes depois da alta estarão sujeitos a tais acontecimentos e por isso devem saber lidar com eles, ou seja, as falhas e equívocos podem ser vistas como "oportunidade de aprendizado e fortalecimento de suas habilidades, diminuindo suas probabilidades de recaída no futuro" (14:178).

No grupo, os profissionais de psicologia e serviço social, utilizam material de apoio bastante comum nas abordagens cognitivo-comportamental, tais como questionários, formulários, testes, entre outros que são chamados de tarefas. Estas tarefas são trabalhadas nas sessões e servem como parâmetro para o trabalho terapêutico. São realizados também grupos de sentimentos, diariamente, iniciando com um breve alongamento, coordenado pelo paciente que está há mais tempo no grupo, nestes os temas abordados relacionam-se aos sentimentos em relação às drogas, evitando a exposição de conteúdos pessoais, o paciente deve-se sentir acolhido elivre para falar 
o que está sentindo naquele momento.

Os grupos e entrevistas com familiares, tem por objetivo a informação a respeito do manejo do paciente em recuperação. A ssim, os familiares são orientados no internamento, para comparecerem à entrevista real izada pela assistente social ou pela psicóloga, a fim de coletar dados relativos à história do paciente, relações familiares etc. Já nas orientações familiares são informados sobre as condutas a serem realizadas com o paciente, assim como aspectos que envolvem o uso de substância, enfatizando que a família é parte fundamental no tratamento do paciente. Essas orientações são real izadas durante o horário de visita, uma vez que muitos familiares são de outras cidades e não tem condições de retornar em outro horário. A ssim, destacamos que

o trabalho de orientação e sensibilização familiar, no modelo cognitivo, tem por objetivo incrementar a qualidade nas relações do grupo familiar, obtendo ganhos tanto para os familiares quanto para a recuperação dos dependentes (15:125).

\section{CONSIDERAÇÕES FINAIS}

0 paciente dependente químico, ao se internar em unidade de dependência química de um hospital geral, vai sentir-se como qualquer outro paciente que deixou de assumir responsabilidades por suas decisões e ações, tendo que sujeitar-se às condiç̧̃es impostas pelo seu quadro, pelo regulamento do hospital e pelo tratamento que irá receber. Para pacientes internados em outras especialidades do hospital, essas experiências seriam no mínimo interpretadas como invasivas e despersonal izantes, mas de acordo com a experiência vivenciada pela equipe, para al guns dependentes químicos essas limitações podem sugerir uma forma de proteção e limites físicos entre o mundo exterior e suas compulsões.

Dessa forma, pode-se pensar que o paciente vê 0 hospital como um meio seguro para se proteger daquilo que ele não está conseguindo controlar. É se retirando da comunidade, por meio de um tratamento programado e estruturado, que ele poderá novamente repensar a respeito de sua vida de maneira global (família, trabal ho, amigos), visto que provavelmente todas as áreas da sua vida foram de al guma maneira afetadas pelo consumo de substâncias.

Essa particulariedade, assim como o meio sóciocultural da região, propiciou à equipe elaborar uma proposta de tratamento que se adapte à clientela de baixa renda, assim como pessoas com menor índice de escolaridade. B usca-se então, propor diálogos e atividades que se aproximem ao máximo possível de sua realidade, facilitando o entendimento e 0 engajamento no tratamento.

A lém disso, verificou-se teoricamente o que já havia sido vivenciado na prática: a importância do trabal ho em equipe. A equipe precisa estar em completa sintonia para que 0 paciente tenha a atenção necessária no tratamento.
A ssim, vê-se a relevância desse estudo para 0 meio científico, uma vez queé escasso o tratamento para paciente dependente químico em unidade de psiquiatria em Hospital Geral, principalmente para pacientes atendidos pelo Sistema Ú nico de Saúde (SUS).

ABSTRACT: This paper suggests a treatment proposal for drug dependents of the psychiatric ward of a main Hospital, more specifically the "Santa Casa de I rati" - Paraná State/ $B$ razil, which is a reference for other eight neighboring municipalities. The purpose is to inform about the work which has been developed in the drug dependence area in general hospitals. Therefore, a therapeutic plan was elaborated in order to enable health care workers to act properly during outbursts, prevent relapses and also contribute for a short-term rehabilitation, working together with the patient's relatives. In order to support this proposal, data of al cohol and drug dependent patients were collected in 2002, along with a literature review to outline the profile of those patients who search for this service.

KEY WORDS: Humanizing; Psychietric reform; Street drugs.

RESUMEN: Este estudio se refiere al relato de la propuesta de trabajo de tratamiento de la persona con dependencia química en Enfermería de Psiquiatria (EPs) de un hospital general, el de Santa Casa do Irati, Paraná, que es hospital de referencia para otros ocho municipios vecinos. Su objetivo es divul gar lo que se está desarrollando en el campo de las dependencias químicas en hospital general. A sí, el tema elegido partió del trabajo que se está desarrollando en Ia Santa Casa do I rati, donde se há constatado la necesidad de reestructuración del tratamiento del dependiente químico, ahora tratado como cualquier outro individuo de atención médica, psicológica y social, intentando no repetir estigmas del hospital psiquiátrico convencional. A sí, se elaboró un plan terapéutico que posibilita a los profesionales de la sal ud actuar junto al dependiente químico en el momento de crisis, en la prevención de la recaída y en la rehabilitación en un corto espacio de tiempo, of reciendo soporte a ese y a su familia, por medio de una atención rápida y eficiente. Para hacer el embasamiento a esta propuesta, se recogieron datos relativos al año de 2002, de pacientes internados por alcoholismo y otras drogas, concomitante con una investigación bibliográfica para establecer un perfil de pacientes que buscan este tipo de servicio.

PALABRAS CLAVES: Dependencia Química; Humanización de la A sistencia; R eforma Psiquiátrica.

\section{REFERÊNCIAS}

1. B otega NJ. Prática psiquiátrica no hospital geral: interconsulta e emer-

Cogitare Enferm 2005 mai/ago; 10(2):54-62 
gência. Porto A legre: A rtmed; 2002.

2. B otega N J. Serviços de psiquiatria no hospital geral. São Paulo: Papirus; 1995.

3. Bertolote JM, Ramos SP. A Icoolismo hoje. 3. ed. Porto alegre: A rtes M édicas; 1997.

4. Ministério da Saúde (BR). A política do M inistério da Saúde para a atenção integral a usuários de álcool e outras drogas. Brasília; 2003.

5. Griffith E. O Tratamento do alcoolismo. São Paulo: M artins Fontes; 1987.

6. Brasil. Portaria M inesterial № 817, de 30 de abril de 2002. Diário Oficial da União. Braślia, 20 trim.; 2002.

7. B rasil. Exigências mínimas para o funcionamento de serviços de atencão a pessoas com transtornos decorrentes do uso ou abuso de substâncias psicoativas. Diário Oficial da U nião de 31 de maio de 200. B rasília, 2o trim. , 2002.

8. N eumann BG. Terapias breves. In: B ertolote J M, Ramos SP. A Icoolismo hoje. 3. ed. Porto A legre: A rtes M édicas; 1997. p. 160-71.

9. Woitowitz AB. A A bordagem do alcoolismo. In: B ertolote JM, Ramos SP. A I coolismo hoje. 3. ed. Porto A legre: A rtes M édicas; 1997. p. 141-7.

10. M anual diagnóstico e estatístico de transtornos mentais. 4. ed. Porto A legre: A rtmed; 2002.

11. M arques A CPR. A bordagem geral. In: Laranjeira $R$, Alves HNP, Baltieri DA, et al. Usuários de substâncias psicoativas: aborgagem, diagnóstico e tratamento. 2. ed. São Paulo: Conselho Regional de M edicina do Estado de São Paulo/ A ssociação M édica Brasileira; 2003. p. 11-27.

12. Ramos SP, B ertolote J M . A Icoolismo hoje. 3. ed. Porto A legre: A rtes M édicas; 1997.

13. Stuart GW, L araia M T. Enfermagem psiquiátrica. 4.ed. Rio de J aneiro: Reichmann e Á fono editores; 2002.

14. K napp P. Prevenção de recaída. In: B ertolote J M, Ramos SP. A Icoolismo hoje. 3. ed. Porto A legre: A rtes M édicas; 1997. p. 173-95.

15. Figlie NB, Pillon SC. Orientação familiar em dependência química. In: Focchi GRA, L eite M C, Laranjeira R, et al. Dependência química: N ovos modelos de tratamento. São Paulo: Roca; 2001. p. 125-41.

ENDEREÇO DOSAUTORES:

Rua Zeferino Bitencourt, 1111

Irati/PR

84500-000

Cogitare Enferm 2005 mai/ago; 10(2):54-62 